\title{
0 arco-íris em foco: a linguagem como mediação do ensino e da aprendizagem sobre conhecimentos físicos
}

\author{
MARIA NIZETE DE AZEVEDO \\ Universidade Federal do Estado de São Paulo, Diadema, SP, Brasil
}

MARIA LÚCIA VITAL DOS SANTOS ABIB Universidade de São Paulo, São Paulo, SP, Brasil

\section{RESUMO}

A linguagem como meio de comunicação social e como meio para ensinar e aprender é o pressuposto básico deste trabalho, cujo interesse é saber como professor e estudantes se comunicam e como se medeia a aprendizagem de conhecimentos científicos com crianças do primeiro ano de escolarização. Exploramos dados alçados de uma pesquisa mais ampla, que focalizou o processo formativo ocorrido em uma escola pública. A análise privilegia o movimento dialógico discursivo em aulas de ciências. Os resultados, analisados sob uma abordagem qualitativa, mostram como a professora mediatiza a comunicação e promove os primeiros passos para um processo de enculturação científica com a criação de contextos de aprendizagem linguísticos e não linguísticos. Os resultados ainda reafirmam a importância de se estudar a dialogia em aulas de ciências como meio para problematizar a aprendizagem do professor em relação aos modos como ele medeia a aprendizagem, o que pode contribuir com renovações para esse ensino.

\section{PALAVRAS-CHAVE}

linguagem e comunicação em aulas de ciências; ensinar a falar ciências; ensino de ciências nos anos iniciais de escolarização. 
THE RAINBOW IN FOCUS: LANGUAGE AS A

MEANS OF MEDIATION IN TEACHING AND

LEARNING OF PHYSICAL KNOWLEDGE

\section{ABSTRACT}

Language as a means of social communication and as a teaching and learning tool is the basic principle of this work, which seeks to understand how teacher and students communicate and how the learning of scientific knowledge is mediated for children in their first school year. We explore data taken from a broader research that focused on a formation process in a public school. This analysis focuses on the discursive dialogue movement in Science classes. Results analyzed under a qualitative approach show how the teacher mediates communication and promotes the first steps in scientific culture acquisition process by creating linguistic and non-linguistic learning contexts. Results reaffirm the importance of studying rhetoric in Science classes in order to discuss teachers' understanding of how they mediate learning, which may contribute to the renewal of this teaching.

KEYWORDS

language and communication in Science classes; teaching to talk about Science; teaching Sciences in first school years.

\section{EL ARCO IRIS EN FOCO: EL LENGUAJE COMO MEDIADOR DE LA ENSEÑANZA Y DEL APRENDIZAJE SOBRE LOS CONOCIMIENTOS FÍSICOS}

\section{RESUMEN}

El lenguaje como medio de comunicación social y como medio para enseñar y aprender es la premisa básica de este trabajo, cuyo interés es saber cómo el profesor y los estudiantes se comunican, y cómo se mide el aprendizaje de conocimientos científicos con niños del primer año de la escuela. Analizamos datos recogidos de una investigación más amplia, la cual se centró en un proceso formativo ocurrido en una escuela pública. El análisis privilegia el movimiento discursivo dialógico en las clases de ciencias. Los resultados, analizados sobre un abordaje cualitativo, muestran como la profesora hace la mediación de la comunicación y promueve los primeros pasos para un proceso de enculturación científica con la creación de contextos de aprendizaje lingüísticos y no lingüísticos. Los resultados reafirman la importancia de estudiar la dialogia en las clases de ciencias como medio para problematizar el aprendizaje del profesor en relación a los modos como él mide el aprendizaje, lo que puede contribuir a nuevos aportes para la enseñanza.

\section{PALABRAS CLAVE}

lenguaje y comunicación en clases de ciencias; enseñar a hablar de ciencias; enseñanza de ciencias en los primeros años de escolarización. 


\section{INTRODUÇÃO}

A aprendizagem docente, discutida pelo olhar sobre modos de mediação docente em aulas de ciências, constitui o corpo temático deste trabalho. As discussões são orientadas pela seguinte pergunta: como uma professora, que deseja ensinar sobre a formação do arco-íris, pode mediar o processo de comunicação, por conseguinte, de aprendizagem de conhecimentos científicos com crianças do primeiro ano de escolarização? Como se configura o padrão de diálogos? Quais instrumentos e signos são interpostos no movimento dialógico discursivo, entre o professor e a criança em aprendizagem?

O processo de aprendizagem docente é estudado no contexto em que se evidencia o como ensinar ciências, com destaque para o papel da linguagem como meio de comunicação e de construção de novos significados. A sala de aula de ciências, considerada uma comunidade de aprendizagem, é o lugar de onde emanam as relações dialógicas, por sua vez oriundas da necessidade de comunicar tanto para ensinar como para aprender. Prezamos pelo conceito de dialogia, o qual tem o sentido que lhe foi atribuído por Bakhtin (2010), o de se referir às muitas formas como duas ou mais vozes entram em contato, cuja análise requer o entendimento da relação de uma enunciação com outras enunciações. Para compreender o que um sujeito diz, é preciso considerar as demais vozes da conversação.

A professora em análise participa de um processo formativo centrado em uma escola municipal da cidade de São Paulo, o qual é orientado metodologicamente pela realização de atividades investigativas de ensino. Professores em coletivo delimitam problemas de ensino, planejam ações para resolvê-los, observam e analisam resultados e replanejam ações. Esse movimento, combinado a ações de estudos e repetido periodicamente, articula um modo de organização do ensino de ciências com possibilidades de promover aprendizagem docente mediada pela associação entre o pensar e o fazer docente, entre estudar, planejar e praticar em sala de aula.

A relevância da discussão proposta situa-se no âmbito da necessidade de renovação do ensino de ciências, da busca por caminhos que conduzam à superação da reconhecida crise que acomete o ensino de modo geral, particularmente o ensino de ciências. Conhecer com mais profundidade modos como o professor articula ações e linguagem para mediar as relações discursivas em aula pode nos aproximar do como se aprende a ensinar ciências e de como se aprende ciências, além de nos subsidiar com novas contribuições para as reflexões no campo da pesquisa em ensino de ciências e da formação permanente de professores.

\section{CONSIDERAÇÕES TEÓRICAS}

\section{MEDIAÇÃO E LINGUAGEM}

O conceito de mediação permeia a concepção marxista e, sobretudo, a obra de Vigotski, como a chave para explicar o desenvolvimento humano na relação homem/natureza, em que a ação humana não se estabelece de forma direta e imediata, mas interposta por instrumentos e signos ou instrumentos psicológi- 
cos. Como o próprio termo já sugere, mediar é colocar-se entre; e de fato não há atividade mediada sem elementos interpostos entre o homem e o seu objeto de trabalho ou entre a criança e o seu brinquedo, ou ainda entre o estudante e o seu objeto de aprendizagem, ou mesmo entre duas pessoas, ao realizarem qualquer tipo de ação conjunta.

O ensino e a aprendizagem não podem ser entendidos senão como processos resultantes de um conjunto de ações mediadas, com grande variedade de elos intermediadores, ora o outro (professor, estudantes etc.), ora instrumentos materiais (livros, cadernos e tantos outros de orientação externa), ora signos ou instrumentos psicológicos de orientação interna (palavra, lembranças, conhecimentos, pensamentos). Seja signo ou instrumento, esses elementos fundem-se nas funções desempenhadas pela linguagem: planejamento, análise, síntese, em suma, comunicação. Não há dúvida de que a linguagem, em qualquer fase do desenvolvimento humano, é o instrumento/signo que reúne infinidades de funções semióticas.

\section{MEDIAÇÃO, LINGUAGEM E COMUNICAÇÃO EM AULAS DE CIÊNCIAS}

Linguagem e mediação em aulas de ciências são temas recorrentes em muitas pesquisas, que se vêm constituindo como um foco de investigação cada vez mais abrangente. Dado ao grande número de trabalhos incluídos nesse campo de estudo, fala-se em uma virada discursiva, movimento assim chamado por centrar atenção no processo de comunicação e de mediação por meio da linguagem, nos discursos e em outros mecanismos retóricos utilizados pelos sujeitos no processo de ensino e aprendizagem (Mortimer e Scott, 2002).

As investigações incluídas na virada discursiva são consideradas relevantes exatamente por trazerem à luz elementos essenciais que emergem das complexas relações que constituem os atos de ensinar e de aprender. O modo como os significados são construídos no contexto da sala de aula, no processo dialógico estabelecido entre os sujeitos, toma o lugar da atenção centrada no desenvolvimento cognitivo do indivíduo. $O$ foco passa a ser a mediação por meio da linguagem e os diferentes discursos no processo de significação desenvolvido entre os sujeitos no contexto coletivo da sala de aula. Não mais se isola como sujeito o aluno ou o professor - um e outro são estudados no processo de ensino e aprendizagem, em que as diferentes vozes se inter-relacionam no movimento dialógico.

Alguns estudos não muito recentes, como os de Mehan (1979), investigam a estrutura de aulas e como as interações são mediatizadas por padrões diferenciados de diálogos e perguntas; Edwards e Mercer (1988) apresentam estudos valiosos por investigarem o modo como a linguagem é apropriada por sujeitos no processo em que o conhecimento é construído e compartilhado em sala de aula; Mercer, em 1997, divulga alguns estudos sobre as "técnicas de linguagem" utilizadas por professores para guiar a construção de conhecimentos; Candela (1999) volta a sua atenção para os discursos em aula, com ênfase nas explicações, justificativas e argumentações feitas por estudantes ao se comunicarem com seus professores; Lemke, em 1997, por sua vez, discute sobre a linguagem, com destaque para a análise de padrões temáticos em aulas de ciências, com a intenção de compreender como professores e alunos falam ciências. 
Trabalhos mais recentes, não menos importantes, analisam diferentes aspectos apreendidos do contexto de comunicação da sala de aula de ciências, os quais, em sua maioria, privilegiam, como objeto de estudo, a construção de significados e a promoção da enculturação científica pelo estudante com o olhar sobre as interações discursivas (Dionne, 2007; Jan, Chee e Tan, 2010; López Rodríguez e Jiménez Aleixandre, 2007; Maximo-Pereira, 2013; Pedrancini, Corazza-Nunes e Galuch 2011; Roth e Lawless, 2002; Sasseron e Carvalho, 2008, 2014; e outros).

No âmbito desses estudos, os processos de aprendizagem "estão profundamente associados à aquisição e ao uso da linguagem em contextos específicos"(Vieira e Nascimento, 2009, p. 444). Em cada contexto, os significados construídos pelos estudantes podem ser expressos, ou melhor, como diz Vigotski (2009), "realizados", por meio da fala, da escrita, gestos, desenhos, entre outros recursos linguísticos. Reitera-se, desse modo, a linguagem como a verbalização das formas internas do pensamento, consubstanciada em um importante recurso de mediação semiótica e de mediatização da comunicação e compreensão e, por suposto, da viabilização da aprendizagem. A linguagem realiza-se como o signo/instrumento da aprendizagem por ser usada na atividade de "interpensar", ou seja, como instrumento usado para se "pensar conjuntamente, para compreender a experiência e resolver problemas coletivamente" (Mercer, 2000, p. 17).

Esses trabalhos, tantos os mais remotos quanto os mais recentes, embora considerem as múltiplas vozes e os modos de realização da linguagem em sala de aula, bem como os diferentes modos de mediação, estratégias e intervenções que compõem as ações e discurso docente, focalizam, em primeiro plano, o movimento discursivo dos estudantes. As intervenções docentes são analisadas e consideradas ponto de referência para o estudo da aprendizagem do estudante no processo dialógico. A formação e a aprendizagem do professor são temáticas que ainda comparecem em pequena quantidade nas pesquisas inseridas no campo da linguagem em aulas de ciências. Eis alguns trabalhos a respeito: Andrade e Martins (2006); Lima e Maués (2006); Scarinci e Pacca (2009); Vieira e Nascimento (2009); Azevedo (2013a); Ortega, Bargalló e Alzate (2014).

Contudo, ainda que não abordem diretamente a formação de professores, muitos dos trabalhos supracitados, ao tecerem suas análises e resultados, indicam importantes elementos que contribuem com os estudos nessa área, por revelarem minúcias do cotidiano da sala de aula, principalmente no que diz respeito aos modos de mediação docente e à dialogia estabelecida entre as enunciações que permeiam as relações entre os sujeitos, e os desafios de se ensinar e de se aprender os variados significados imanentes à cultura científica. Esses estudos analisam a atuação ou modos de mediação docente sob diferenciados aspectos, a saber: intenções, conteúdos de seus discursos, padrões de comunicação e de interações, formas de intervenção, de estratégias e de atitudes, procedimentos didáticos discursivos, entre outros.

\section{COMUNICAÇÃO, ENSINO DE CIÊNCIAS E O PAPEL DO PROFESSOR}

Em uma abordagem geral de estudos que focalizam a linguagem como elemento central para se compreender o ensino e a aprendizagem, constata-se que tanto o ensino como a comunicação são concebidos como processos sociais, o 
que nos faz olhar com mais cuidado para a atuação do professor, valorizando não apenas conhecimentos e atitudes, mas valores e interesses sociais (Lemke, 1997). Sem dúvida, estamos diante de uma nova expectativa quanto ao papel do professor - como um tutor e como usuário da linguagem, esse profissional pode levar os alunos a novos níveis de compreensão conceitual mediante a fala com eles, ou seja, mediante a comunicação (Edwards e Mercer, 1988). Não devemos esquecer que a linguagem é tanto instrumento como signo mediacional do professor e do estudante, usado, exaustivamente, tanto para ensinar como para aprender por ambos os sujeitos.

O grande desafio do professor, ao assumir esse novo papel, é transformar sua sala de aula em uma comunidade, na qual a linguagem científica possa ser introduzida, de modo que se ensine e se aprenda a falar ciências. Nessa perspectiva, aprender ciências consiste em aprender a falar ciências, o que não se traduz na repetição de conhecimentos transmitidos por outros e nem na expressão de termos científicos isolados entre si; falar ciências significa comunicar ciências, fazer ciências por meio da linguagem (Jan, Chee e Tan, 2010; Lemke, 1997).

Contudo, estabelecer a comunicação em aulas de ciências, seja para crianças ou para adolescentes e adultos, não é algo simples e corriqueiro. Ao contrário, como afirma Lemke (1997), nem sempre professores e alunos se comunicam, pois a linguagem pode ser usada de formas diferentes por esses sujeitos: professores podem falar ciências enquanto alunos podem não fazê-lo; alunos podem, por exemplo, apresentar padrões temáticos conflituosos em relação aos desenvolvidos pelos professores.

Segundo Edwards e Mercer (1988), não se pode deixar de levar em conta os muitos aspectos que influenciam e até limitam o processo de comunicação em classe, nem minimizar as responsabilidades do professor, visto socialmente como representante de uma cultura e de um corpo de conhecimentos. Ao focalizarmos o professor de ciências dos anos iniciais, suas dificuldades imediatas são consideradas, bem como os limites de recursos diante da sua responsabilidade de ensinar para um grupo de crianças.

Ensinar crianças a falar ciências constitui-se em um desafio para o professor desse nível de ensino, cuja formação polivalente nem sempre o prepara adequadamente para ensinar ciências especificamente. Embora a ideia de que esse professor não se sente preparado e seguro para ensinar ciências seja consensual em muitos estudos (Appleton e Kindt, 1992; Paixão e Cachapuz, 1999), alguns autores, entre eles Lima e Maués (2006), relativizam esses resultados ao questionarem se o fato de se ter pouco conhecimento dos conteúdos conceituais influencia de forma crucial o ensino. Para essas autoras, dois aspectos devem ser lembrados: o de que as dificuldades sobre os conteúdos acometem professores dos diferentes níveis do ensino; e o de que professores polivalentes são capazes de mobilizar conhecimentos das outras áreas, o que pode enriquecer o processo de ensino/aprendizagem e reparar determinadas deficiências.

A reflexão sobre tais resultados deve ter o cuidado de nem sobrecarregar o professor e de nem isentá-lo do domínio sobre os conteúdos. Evidentemente, não é possível ter domínio pleno sobre os conteúdos, e nem a total segurança sobre o ensino se justifica apenas sobre esse domínio, entretanto não há como negar que determinado nível de conhecimento sobre o que se está ensinando é importante. 
O conhecimento é, a um só tempo, matéria-prima e instrumento/signo do professor, sobretudo quando se está inserido em um contexto profissional, no qual se privilegia a docência constituída pelos atos de planejar, desenvolver e interpretar. Nesse contexto, a deficiência em relação aos conteúdos pode ser superada por meio do trabalho coletivo e da prática do estudo e da pesquisa. A predisposição ao estudo e à pesquisa pode ser considerada um compromisso epistemológico do professor com os conhecimentos da área, o que lhe possibilitará ensinar a falar ciências, mesmo que não seja um expert nessa tão complexa área de ensino e de estudo (Azevedo, 2013b).

\section{COMUNICAÇÃO, DIÁLOGOS E A APRENDIZAGEM EM CIÊNCIAS}

Os muitos estudos sobre linguagem em sala de aula de ciências, anteriormente citados, podem nos falar da versatilidade do professor na busca por atingir seu objetivo mediante seu trabalho, tendo ou não pleno domínio sobre os conteúdos conceituais. Professores lançam mão de diferentes maneiras para ensinar, desde as mais frequentes e que exigem poucos recursos até aquelas mais complexas, com ações experimentais ou com recursos tecnológicos. Os modos de mediação docente são tão diversificados a ponto de levarem autores como Mortimer e Scott (2002, p. 284) a se dizerem impressionados com as variadas maneiras pelas quais professores medeiam a relação com seus estudantes: "em algumas salas, as palavras estão por toda parte".

Para Vieira e Nascimento (2009), essas variadas maneiras de gerenciamento e controle sobre o movimento dialógico em sala de aula podem estar relacionadas aos modos como se concebe o processo de construção de sentidos pelos estudantes, em meio à diversidade de intervenções docentes em contextos em que se valoriza a aprendizagem mediante a comunicação. Possivelmente, as intervenções do professor que privilegiam a transmissão de conhecimentos e a sua recepção pelos estudantes podem não ser tão diversificadas nem favorecer uma "[...] relação autoral dos estudantes com o conhecimento científico escolar" (Freitas e Aguiar Júnior, 2012, p. 26).

Esse processo de comunicação em aulas de ciências tem sido estudado a partir de padrões de diálogo. É consensual a presença do diálogo triádico, aquele municiado por pergunta, resposta e avaliação, cuja sequência de fala é iniciada por uma pergunta avaliativa ou de exame e finalizada pelo professor por uma avaliação (Edwards e Mercer, 1988; Jan, Chee e Tan, 2010; Lemke, 1997; Mehan, 1979; Wertsch, 1999; e outros). Nesse modelo de diálogo, o professor inicia o diálogo (I), os estudantes respondem $(\mathrm{R})$ e o professor dá o retorno avaliativo (E). Aos olhos desses pesquisadores, essa relação tripartida ou padrão I-R-E (initiation - response - evaluation) reflete elementos essenciais do discurso estabelecido entre professor e estudantes, frequente e predominante em contextos em que se privilegia a transmissão unidirecional de conhecimentos.

Entre esses elementos, podemos destacar o fato de que a maioria das perguntas é feita pelo docente com intenções que vão desde checar o conhecimento do estudante a controlar as relações de poder e autoridade na classe. Por meio desse padrão de diálogo, a relação de poder é assimétrica, em que o professor detém quase que completamente o discurso, restando para o aluno o papel de responder as perguntas que the são dirigidas. 
Outro elemento refletido pelo padrão I-R-E avaliativo é a relação do professor sobre o conhecimento ou padrão temático em desenvolvimento na aula. Essa relação de domínio ou de aparente domínio é revelada pelo fato de o professor perguntar o que já se sabe, ou seja, o que já se pode prever como resposta. Muitas vezes, repete a resposta do aluno, avaliando-a positivamente; em caso de não se obter a resposta desejada, fica em silêncio ou repete a pergunta. Nas aulas em que se verifica o predomínio desse padrão de diálogo, os estudantes perguntam menos, falam muito pouco e escrevem menos (Lemke, 1997).

Embora a permanência desse modelo de diálogo seja avaliada como de pouco impacto positivo para o processo de aprendizagem dos estudantes, alguns estudos ponderam esses resultados, ao suporem que as perguntas que iniciam a sequência das falas, mesmo em caráter avaliativo, podem ser eficazes e podem ser consideradas importantes e produtivas para a educação (Wertsch, 1999). A principal reclamação se situa em seu predomínio, tomando o lugar das cadeias de diálogo mais abertas, em que a participação e a voz do aluno são mais valorizadas. Segundo Capecchi, Carvalho e Silva (2000), mesmo sob o padrão I-R-E, verifica-se que, se o professor, em vez de avaliar a resposta do estudante, acrescentasse novas ideias à discussão, estaria em certa medida introduzindo um novo padrão e enriquecendo a comunicação em sua aula.

Todavia, há quem tenha outra avaliação. Para Lemke (1997), por exemplo, a aula bem poderia ser organizada de modo que os alunos dispusessem de mais tempo para perguntas, intervenções, dúvidas, discussões orais acerca de temas e escritas sobre o assunto, além de trabalharem em grupo. Nessa mesma direção, outros estudos indicam que nem sempre a sequência de fala finaliza com a avaliação feita pelo professor sobre a resposta do aluno, com destaque para a presença de cadeias de diálogo abertas em diferentes processos de comunicação observados. Monteiro e Teixeira (2004) são alguns dos autores que evidenciam situações em que a iniciação enunciada pelo professor é a introdução de um problema, sendo este sequenciado por intervenções dos alunos, que podem ser respostas ou perguntas. A última pessoa da cadeia não é necessariamente o professor, e, se for, não necessariamente profere uma enunciação avaliativa.

No âmbito desses contextos, presenciam-se perguntas chamadas autênticas, tanto enunciadas pelo professor como pelos alunos, caracterizadas como aquelas em que o locutor não tem uma resposta preestabelecida: pergunta-se sobre o que não se sabe e se deseja saber. Segundo Wertsch (1999), as perguntas autênticas compõem contextos de comunicação dialógicos, nos quais o professor, ao perguntar, assinala para os alunos interesse pelo que eles pensam e sabem; convida os alunos a contribuir com algo novo à discussão, podendo mudá-la ou modificá-la de alguma maneira. Em tais situações, contamos com perguntas proferidas por estudantes quase sempre sob o caráter de autenticidade, pois esses, sobretudo quando são crianças, perguntam porque querem saber e dificilmente perguntam para testar ou avaliar o conhecimento do professor.

É consensual no corpo dos trabalhos referenciados a ideia de que os estudantes falam e perguntam mais em contextos em que as intervenções docentes são mais diversificadas. Quanto mais variados forem os modos de mediação, mais 
se contribui para o enriquecimento do processo de comunicação, sobretudo no que diz respeito à participação dos estudantes e possibilidades de aprendizagem. As perguntas docentes incluem-se entre os armamentos discursivos adotados para mediar a comunicação, "[...] dirigir o pensamento e ação dos alunos e estabelecer os limites da atenção compartilhada, da atividade conjunta e do conhecimento comum" (Edwards e Mercer, 1988, p. 62). Souza (2012) corrobora tal inferência ao abordar a relação entre a qualidade e a importância das perguntas docentes e o objetivo de alfabetizar cientificamente os alunos. No entendimento desse autor, com o qual estamos de acordo, perguntas proferidas com a intenção de problematizar, explorar dados e processos e perguntas para fins de sistematização podem ser consideradas indicadores de alfabetização científica dos alunos.

Além da variedade dos modos de mediação, a qualidade e o conteúdo dos discursos no processo dialógico também influenciam essa participação. Tal consenso reforça a necessidade de se investir em mais pesquisas e produções de conhecimento no campo da formação docente com o olhar para o movimento dialógico em sala de aula, de modo que se problematize não simplesmente o conteúdo do discurso do professor, mas como esse discurso poderia ocupar-se majoritariamente da construção de um ensino que objetivasse a criação de necessidades e motivos de aprendizagem para os sujeitos envolvidos: professores e estudantes.

\section{MEDIAÇÃO, ENSINO POR INVESTIGAÇÃO E A}

\section{APRENDIZAGEM DE CONHECIMENTOS FÍSICOS: A PESQUISA}

Neste trabalho analisamos como professora e crianças de uma classe de trinta alunos do $1^{\circ}$ ano do ensino fundamental I se comunicam, como se dá a mediação da aprendizagem de conhecimentos físicos para e com crianças de 6 a 7 anos. A professora, cuja aula fornece os dados analisados, trabalha em uma escola pública da rede municipal de ensino da cidade de São Paulo e participa com mais catorze professoras de uma formação contínua em serviço em ensino de ciências, organizada por meio de atividades investigativas de ensino. São professoras dos anos iniciais, entre essas, seis trabalham com classes de $1^{\circ}$ ano.

A realização de atividades investigativas de ensino traduz-se na organização e prática do ensino na escola em um ciclo de ações que engloba estudos, planejamento, desenvolvimento e reflexões individuais e coletivas. Necessidades de garantir a aprendizagem e objetivos previamente delimitados são transformados em problemas de ensino, os quais, uma vez explicitados, mobilizam o coletivo docente a planejar ações estruturadas como atividades investigativas de aprendizagem que são desenvolvidas pelos alunos em sala de aula. Interpretar, analisar e refletir individualmente e coletivamente sobre esses resultados pode levar a reformulações e a delimitações de novos problemas de ensino e ao reinício de outros ciclos investigativos, que buscam melhorar os processos de ensino e aprendizagem em ciências.

Nesse contexto formativo, há algum tempo esse grupo docente experimenta uma prática distinta daquela denominada "tradicional" (Mizukami, 1986) para o ensino de ciências, com a intenção de construir uma proposta metodológica coerente com o contexto social e cultural, no qual a escola e sua comunidade estão inseridas. 
Essa proposta metodológica em construção sofre influências de pressupostos da teoria histórica e cultural, em que a atividade investigativa é privilegiada como um processo que organiza tanto o ensino como a aprendizagem de conhecimentos a partir da criação de situações de aprendizagem baseada na colaboração e na comunicação entre sujeitos. Tais situações de aprendizagem são orientadas por um problema, em que os alunos planejam e desenvolvem estratégias de investigação a fim de resolvê-lo, sendo essa resolução o próprio caminho que conduz e realiza a aprendizagem. $\mathrm{O}$ sentido atribuído à aprendizagem condiz com pressupostos vigotskianos, entendida como um processo social, por meio do qual crianças penetram na vida intelectual dos adultos que a cercam (Vigotski, 2010).

Assim, entre as diferentes formas de encaminhar possibilidades inovadoras de trabalho, as docentes buscavam, de modo coerente com o próprio processo de formação em que estavam envolvidas, desenvolver em suas classes atividades investigativas de aprendizagem, compatíveis com a perspectiva de ensino por investigação, bastante difundido em propostas presentes na literatura da área, como em Azevedo (2004), Azevedo (2013a) e em Maximo-Pereira (2014).

\section{METODOLOGIA}

Os dados alçados neste trabalho constituem o banco de dados de uma pesquisa acadêmica (Azevedo, 2008) realizada sobre o processo de aprendizagem da docência das professoras que compõe o processo formativo antes referenciado. Os dados foram obtidos por meio de entrevistas, filmagem de reuniões e de aulas. Entre as atividades investigativas de ensino realizadas, escolhemos para análise a atividade denominada "arco-íris na escola", por expressar com riqueza de dados o desafio de buscar ensinar sobre a formação do arco-íris para crianças de 6 a 7 anos. Essa atividade é composta de fases de planejamento, desenvolvimento das ações com os alunos e reflexão coletiva entre as docentes. As ações elaboradas pelo coletivo foram postas em prática nas seis classes do $1^{\circ}$ ano, embora apresentemos dados de apenas uma das classes.

\section{SOBRE A ATIVIDADE INVESTIGATIVA DE ENSINO “ARCO-ÍRIS NA ESCOLA"}

A atividade investigativa de ensino "arco-íris na escola" foi planejada com base em referenciais construídos pelo próprio grupo docente em formação, cujos conteúdos escolhidos se articulam com objetivos do ensino: incentivar a investigação e a observação do que acontece ao redor; incentivar a observação de um fenômeno nunca antes pensado pelas crianças; introduzir o estudo das cores a partir da beleza do arco-íris; criar situações reais de escrita e de leitura para garantir a alfabetização e o letramento e introduzir o conceito científico da decomposição da luz branca do sol ao entrar e sair de uma gota d'água, formando as cores do arco-íris. Com base nesse conjunto de intenções, o problema de ensino foi delimitado: "como levar as crianças a aprender sobre a formação do arco-íris". 
Ao iniciar o planejamento das ações, as professoras se depararam com a complexidade dos conhecimentos físicos e com suas próprias dificuldades, o que as mobilizaram a estudar coletivamente sobre os conteúdos relativos às explicações científicas sobre o fenômeno em pauta para que conseguissem estruturar as atividades que seriam desenvolvidas em classe com os alunos. São professoras cuja formação polivalente não promoveu o aprofundamento adequado para o ensino de ciências.

Após vários estudos e discussões, decidiram começar com algumas estratégias de sensibilização e por duas questões consideradas problemas: como o arco-íris se forma no céu e como podemos formar um arco-íris na escola. Estruturaram-se então as aulas, que desencadeariam nas crianças o processo denominado pelas professoras de "investigativo", composta de duas principais atividades investigativas de aprendizagens, cada qual envolvida pelas questões-problema definidas pelas professoras. Não se imaginava como se comportariam as crianças e nem se apresentariam conhecimentos prévios sobre a formação do arco-íris ou até se conseguiriam sugerir ações para resolver os problemas propostos. Restava às professoras apenas testar suas hipóteses de trabalho e observar os resultados.

\section{ANÁLISE E RESULTADOS}

Como o foco de análise deste trabalho é a mediação da dialogia em sala de aula, foram delimitados episódios de ensino, como definidos por Carvalho (1993, p. 185):

Chamamos de episódio de ensino aquele momento em que fica evidente a situação que queremos investigar. Pode ser a aprendizagem de um conceito, a situação dos alunos levantando as hipóteses num problema aberto, as falas dos alunos após uma pergunta desestruturadora, etc. Ele é parte do ensino, um recorte feito na aula, uma sequência selecionada que se caracteriza por processos de busca da resposta do problema em questão.

Em nosso caso, os episódios constituem-se em segmentos das transcrições das filmagens das aulas, nos quais estão evidentes os aspectos relacionados às atividades investigativas de aprendizagem.

A sequência das aulas registradas constituiu-se de um conjunto extenso de episódios, que enunciamos a seguir:

1. uma conversa informal sobre o tema;

2. a formulação do primeiro problema;

3. escrita das hipóteses da classe;

4. interações em pequenos grupos;

5. os grupos apresentam suas ideias;

6. compreensão e discussão do segundo problema;

7. escolha da experimentação a ser realizada;

8. conversa preparatória para formar o arco-íris;

9. o encantamento com o arco-íris;

10. a escrita do relatório individual; 
11. por que o arco-íris se forma?;

12. qual a cor da luz do sol;

13. fechamento do ciclo.

Desses episódios, selecionamos para o presente trabalho quatro deles, por conterem, com riqueza de informações, a dialogia estabelecida entre os sujeitos.

A análise qualitativa do movimento dialógico é apoiada na linguagem, concebida como instrumento mediador da comunicação, cuja intenção é evidenciar os seguintes elementos: modos de mediação docente; padrões de relacionamento; padrões de diálogos e padrões temáticos dos discursos.

$\mathrm{Na}$ apresentação dos dados a seguir, a professora da classe é designada de $\mathrm{P}$ e as crianças identificadas pelas siglas $\mathrm{C} 1, \mathrm{C} 2, \mathrm{C} 3$ etc., utilizadas para diferenciação das falas e preservação do anonimato.

\section{EPISÓDIO I: O PRIMEIRO PROBLEMA}

Após uma conversa inicial sobre quem já havia visto um arco-íris, a professora sugere a primeira pergunta, que é respondida pelas crianças organizadas em pequenos grupos.

1. P - Então, como todo mundo aqui conhece o arco-íris, vamos pensar um pouquinho sobre como ele se forma. Agora a prô vai entregar esta fichinha com a pergunta Como se forma o arco-íris no céu? Vou colar no caderno de vocês, e vocês vão explicar em forma de desenho, mas é para escrever também.

[A professora passa em todas as carteiras e cola a "fichinha", que se trata de uma tira de papel, contendo a pergunta. As crianças tentam lê-la, com bastante dificuldade].

2. P - Vamos então ler com a prô. Aqui na lousa, olhem! [As crianças leem a pergunta em coro. A professora orienta a leitura, apontando palavra por palavra].

Esse pequeno episódio mostra a organização do espaço físico da sala, a estrutura da aula e alguns dos signos mediadores interpostos entre a professora e as crianças. O diálogo, mediado pelo objetivo da aula, enunciado e escrito na lousa, ocorre sob orientação e controle da professora: as crianças fazem exatamente o que lhes é pedido. A professora, sempre que preciso, aumenta o tom de voz, emitindo sua voz "pública", como diz Lemke (1997), "sua voz de professor", culturalmente autorizada a essas incursões.

Entretanto, observamos que o padrão de relacionamento favorece a condução da aula, pois as crianças fazem com tranquilidade o que lhes é proposto pela professora. As interações na sala de aula são construções de seus sujeitos, portanto dependente de seus motivos e interesses. Como diz Lemke (1997), um professor não põe uma classe em movimento sozinho, necessita da cooperação dos alunos e, para tanto, o padrão de relacionamento proposto pelo professor desde o primeiro dia é, sem dúvida, fundamental. No caso da classe observada, as relações humanas são regidas de modo muito próximo e afetivo, o que podemos notar nas ações da 
professora ao circular pela classe, ao passar de carteira em carteira e iniciar o diálogo com todos os grupos. Qual o padrão desse diálogo? Veremos a seguir:

\section{EPISÓDIO II: INTERAÇÕES EM PEQUENOS GRUPOS}

A aula prossegue com as crianças organizadas em pequenos grupos. Conversam entre si e escrevem suas ideias para responder ao problema: como o arco-íris se forma no céu? [A professora passa em todos os grupos e conversa com as crianças]:

\section{(Grupo 3)}

1.P - E vocês?

2. C3 - Depois da chuva.

3. P - Você ouviu o que ele falou? Você acha isto também C3? E você, o que você acha? Vocês estão juntos. [...] Ele contou pra você o que ele acha? Então conta pra ela. Você acha que é depois da chuva que forma? Tem mais alguma coisa? Tente escrever e desenhar sobre o que vocês acham que é.

\section{(Grupo 5)}

1.P - E vocês? Vocês já conversaram? O que você contou pro C6?

2. C5 - A chuva cai, vem o sol e forma o arco-íris.

3. $\mathrm{P}-\mathrm{E}$ você $\mathrm{C} 6$, o que acha disto?

4. C6 - O sol vem e a gotinha vai lá e ajunta e vira um arco-íris, que fica rodando.

\section{(Grupo 6)}

1. $\mathrm{P}-\mathrm{O}$ que você, $\mathrm{C} 8$, contou pro $\mathrm{C} 9$ ?

2. C8 - Quando chove tem arco-íris.

3. $\mathbf{P}$ - Toda vez que chove tem arco-íris?

4. C8 - Tem vez que não.

5. $\mathbf{P}$ - Por que tem vez que tem e tem vez que não tem?

6. C9 - Por que se chove muito tem, e quando chove pouco não tem.

7.P - Então desenha e escreva do jeito que vocês acham que é. Que letrinha é que escreve chuva?

[As crianças gesticulam muito para falar: representam a chuva levantando e abaixando os braços e fazem círculos no ar para falar do arco-íris].

Ao final da aula, a professora solicita que as duplas se levantem e apresentem suas ideias para a classe. As crianças vão até a frente e falam o que conversaram. Enquanto isso, a professora vai escrevendo na lousa o que é dito.

Os diálogos ocorridos nos grupos com a participação da professora demonstram o seu papel na mediação entre uma criança e outra. Os signos introduzidos na conversa são desencadeados da questão geral que carrega o objetivo da aula. Desse objetivo demandam demais perguntas e respostas, as quais orientam os diálogos. A professora adota a resposta de uma criança para introduzir a pergunta 
seguinte. Entretanto, é possível notar que a intenção dessas perguntas não é avaliar as respostas dos alunos, e sim, ao que aparenta, mobilizá-las a falar e provocar o diálogo. Notamos em suas enunciações, nos turnos 3 (Grupo 3), 1 e 3 (Grupo 5) e 1 (Grupo 6), que ela coloca uma criança em relação à outra, incitando a comunicação entre elas.

Reforçamos que os diálogos estabelecidos entre os sujeitos no episódio em análise não se incluem no modelo "triádico", estruturado em pergunta-resposta-avaliação (Lemke, 1997), uma vez que as perguntas da professora exercem o papel também de levar as crianças a expor seus conhecimentos sobre o fenômeno em estudo, ou melhor, o de permitir que a professora conheça o padrão temático da classe.

Qual é o padrão temático da classe? Afinal há ciências nos diálogos? A pergunta que orientou as discussões em grupo foi: como se forma o arco-íris no céu? As respostas não apresentam elementos conceituais capazes de explicar o fenômeno de modo científico e nem esperávamos que contivessem, pois se tratam de crianças de 6 a 7 anos, e nessa fase ainda não se opera com conceitos completamente formados, e sim, como classifica Vigotski (2009, p. 193), com pseudoconceitos, o que "[...] pela aparência, praticamente coincide com os significados das palavras para os adultos, mas no seu interior difere profundamente delas". Mais adiante, Vigostski (2009, p. 196) esclarece:

Em termos mais simples, a criança não cria sua linguagem, mas assimila a linguagem pronta dos adultos que a rodeiam. A criança não cria por si mesma complexos correspondentes ao significado das palavras, mas os encontra prontos, classificados com o auxílio de palavras e denominações comuns. Graças a isto, os seus complexos coincidem com os conceitos dos adultos e surge o pseudoconceito - o conceito-complexo.

$\mathrm{Na}$ verdade, a criança opera com suas percepções e não fica presa ao significado da palavra, embora esse signo, no papel de pseudoconceito, assuma a função equivalente do conceito e seja o enlace de comunicação com o adulto. As operações mentais da criança carecem de nexos conceituais próprios da essência dos verdadeiros conceitos, estruturados em sistemas conceituais, o que os torna instrumentos explicativos dos fenômenos. Para Vigotski (2009, p. 227), a formação de conceitos não prescinde do domínio da abstração: "O conceito surge quando uma série de atributos abstraídos torna a sintetizar-se, e quando a síntese abstrata assim obtida se torna basilar de pensamento com o qual a criança percebe e toma conhecimento da realidade que a cerca".

No caso em questão, as crianças não operam com os nexos conceituais que compõem o núcleo do conceito de refração da luz para explicar a formação do arco-íris, mas sim com elementos que na aparência se assemelham a esse conceito ou a esse significado. Entretanto, embora as palavras das crianças apenas explicitem a aparência do fenômeno, elas não são vazias, pois contemplam sentidos carregados de vivências relacionadas a regularidades observadas em todas as vezes em que o arco-íris foi visto - o sole a chuva. Os termos sol, chuva, gotinhas e arco-íris contidos nas frases-respostas não estão isolados entre si, ao contrário, há relações entre eles: 
o arco-íris aparece quando chove e tem sol, ou seja, para formar o arco-íris é preciso chover e fazer sol. Há uma combinação entre as palavras ligadas por elementos que, para as crianças, são necessários à formação do arco-íris. A junção desses elementos comporia um aparente sistema que explicaria e significaria o todo possível no plano intelectual dos pequenos estudantes - o plano dos pseudoconceitos.

Contudo, o significado do todo, como diz Lemke (1997), é mais que a soma das partes. Para que o todo possível, aparente, digamos assim, se tornasse compreensível, seria necessário conhecer as relações de significado que há entre as diferentes palavras; seria necessário abstrair e sintetizar, e tornar essa síntese a base do pensamento, o qual, por sua vez, tornar-se-ia signo/instrumento de novas percepções da realidade. Desse modo, o arco-íris seria compreendido sob novos atributos, os quais comporiam um todo, cujas partes, constituídas em uma síntese, mostrariam a essência desse fenômeno. Por isso dizermos que as crianças operam com a aparência do conceito, o que lhes possibilita apenas começar a aprender a falar ciências.

Portanto, se não podemos ainda afirmar que há ciências no diálogo assistido, ousamos dizer que a professora, a partir da sugestão do problema desencadeador do processo investigativo, cria contextos de aprendizagem em que se introduz, por meio do diálogo, alguns elementos mediadores com potenciais para impulsionar o desenvolvimento de funções mentais, como a memória lógica, atenção arbitrária, abstração, comparação, importantes para a formação posterior de conceitos científicos.

\section{EPISÓDIO III: COMPREENSÃO E DISCUSSÃO DO SEGUNDO PROBLEMA - COMO PODEMOS FORMAR UM ARCO-ÍRIS AQUI NA ESCOLA?}

20. $\mathbf{P}$ - Bem, agora eu quero que vocês deem ideia para a prô, pois não sei como vamos fazer. Vocês me contaram como vocês acham que um arco-íris se forma no céu [...]. Agora a prô quer fazer um arco-íris, agora, aqui na escola. Eu queria que vocês dessem várias ideias pra gente fazer um arco-íris. Cada um vai levantar a mão para contar a ideia que tem. Se der certo, a gente vai fazer hoje ainda. Silêncio pra ouvir o amigo. Vamos ouvir.

[As crianças, de mãos levantadas, esperam ansiosas para falar. A ansiedade é expressa nos gestos: levantam e abaixam as mãos; começam a falar e param; arregalam os olhos; falam, ao mesmo tempo. A professora vai indicando a criança que vai falar em cada momento].

21. C1 - Quando eu estou mexendo com água, o reflexo do sol se transforma num arco-íris.

22.P - Alguma vez já aconteceu na casa de vocês? Vocês mexendo com a água e aparecer um arco-íris?

24. C5 - Eu estava tomando banho de mangueira e aí eu comecei a brincar de jogar água e o arco-íris apareceu.

25. C6 - A gente pode descer e molhar lá fora onde está batendo bastante sol e bate o arco-íris.

26. P - Molhar com o quê? Como que vamos jogar a água? Com a mão? 
27. C7 - Com a mangueira.

29. C8 - Quando a minha mãe lava roupa no quintal, eu fico brincando com água. Eu já vi um arco-íris.

30. C8 - Eu estava dando banho na cachorra e joguei água pra cima com a mangueira e vi um arco-íris.

31. P - Quem tem mais uma ideia diferente?

32. C9 - Coloque um espelho dentro da água e coloque um papel no chão e vai aparecer o arco-íris.

33. $\mathbf{P}$ - Como fazer isso? [Surpresa]

34. C9 - Você pega a água, uma folha, espelho, coloca o espelho dentro da água, e vai mexendo o espelho e vai aparecer um arco-íris na folha.

35. P - [...] Então nós tivemos duas ideias, uma que foi jogar água em um lugar iluminado pelo sol. A gente pode usar a mangueira para isso. A outra ideia foi com o espelho, que depois a gente vai conversar melhor sobre essa ideia [a professora sintetiza a conversa].

Destacamos no enunciado da professora (turno 20), o modo como ela introduz a segunda pergunta, tentando caracterizá-la como um problema que nem ela sabia como resolver. Dessa maneira, ela cria um contexto para gerar sentidos para a atividade e, assim, envolver e comprometer o aluno, tornando-o o sujeito mais importante da interação, fazendo-o tomar parte diretamente da solução do problema e até de tomá-lo como seu.

No decorrer do episódio, a professora intervém pontualmente para mediar o diálogo e ouvir o que cada criança tinha a dizer, para garantir a gestão da classe, de modo que uma criança pudesse ouvir a outra. Sabemos que ouvir as crianças, sobretudo em uma classe numerosa, requer, por parte do professor, organização temporal e, acima de tudo, valorização do que está sendo dito por cada criança, para que seja possível alimentar o diálogo e construir com ela novos significados. As crianças estão aprendendo a dialogar, aprendendo a falar e a ouvir. Saber ouvir o outro é, seguramente, uma operação mental importante no desenvolvimento de funções superiores, como atenção e concentração. É um processo de reeducação em que todos têm o seu espaço garantido e respeitado tanto para ouvir como para falar. Como já nos disse Freire (1971), o silêncio no espaço da comunicação possibilita, ao sujeito que ouve, entrar no movimento interno do pensamento de quem fala; e, ao que fala, escutar as indagações e criações de quem está a lhe ouvir.

O que mais se destaca no episódio é, sem dúvida, o movimento discursivo das crianças ao sugerir suas ideias para formar um arco-íris na escola. Incitadas pela professora (turno 22, ao perguntar se o arco-íris já aconteceu na casa), elas apresentam ideias carregadas de cultura e de experiências de vida — suas vivências em seu cotidiano com a família, ainda não ampliadas pelo convívio escolar em virtude do pouco tempo de início de sua escolaridade. Alguns dos elementos culturais relacionam-se a trabalhos domésticos realizados pela criança com o pai ou a mãe, como lavar roupa, lavar quintal, dar banho na cachorra; e outros se relacionam às brincadeiras com água nos dias quentes de verão. Embora as sugestões sejam apresentadas como relatos de vivências, e não propriamente como propostas de ação, é 
possível perceber que as crianças compreenderam o problema; que o arco-íris de fato faz parte de seu universo cultural; que seus conhecimentos e experiências de vida foram ativados, e que foi estabelecida uma relação entre esses conhecimentos e o enunciado apresentado pela professora; que elas, para solucionarem o problema sugerido, recorreram a seus conhecimentos e estratégias pessoais, estabelecendo relação entre esses conhecimentos e o conteúdo do enunciado proposto como estratégia de ensino pela professora.

As propostas das crianças emergidas em todas as classes foram colocadas à mesa de reunião das professoras, as quais, no papel de signos mediadores, constituíram-se em elementos fundamentais para a elaboração das ações seguintes. Transformar sugestões de crianças em ações investigativas, embora aparentemente simples, é uma ação que requer a reelaboração para transformar uma linguagem sem teor epistemológico, sem ciência, digamos assim, em linguagem com ciência, composta de problemas capazes de mobilizar os estudantes à busca de novas ações e de novos significados. Esse processo encerra a complexidade de redimensionar conceitos espontâneos, aproximando-os da linguagem científica, com possibilidades para um redirecionamento do sentido inicialmente atribuído a eles pelas crianças. Essas professoras, envolvidas em tal desafio, criam situações de aprendizagem com potenciais para a realização dos objetivos pretendidos.

Entre as várias sugestões dos pequenos estudantes, a que mais chamou a atenção das docentes foi a de formar o arco-íris usando um borrifador ou pulverizador, apresentada, como as demais, na forma de relato de experiência: "quando espirro água nas plantas da mamãe e faz sol, aparece um arco-íris”.

As professoras, após testarem as sugestões, estruturaram as aulas seguintes e iniciaram o processo de realização. Os próprios alunos de cada classe decidiram a sequência de realização, elegendo, como primeira, a formação do arco-íris com o esguicho da mangueira e, em seguida, a formação do arco-íris com o pulverizador.

\section{EPISÓDIO IV: POR QUE O ARCO-ÍRIS SE FORMA?}

Esse episódio reporta-se a uma conversa realizada no processo de finalização das atividades investigativas de aprendizagem, após experimentações, produções de relatórios e demais ações. Experimentações, como arco-íris com o esguicho da mangueira, arco-íris com o pulverizador, arco-íris nas bolhas de sabão, entre outras. A experimentação arco-íris com o pulverizador, por exemplo, é realizada no pátio da escola, em uma parte ensolarada. Cada criança recebe um pulverizador e o manipula autonomamente, a partir de orientações da professora. A informação de que o arco-íris se forma do lado oposto à posição do sol é uma importante dica fornecida pela professora, a qual se torna o signo mediacional da experimentação: ao ouvi-la, cada criança observa a posição do sol, vira de costas para o astro e espirra água na área iluminada. Por fim, conseguir visualizar o arco-íris torna-se um desafio, enfim resolvido por todos em um clima de euforia e encantamento. Vamos à roda de conversa:

1.P - [...] Agora vamos pensar mais um pouco: o que será que acontece quando essa luz do sol entra nas gotinhas de água pra depois se formar em cores? O que vocês acham que é isso? 
2. C1 - Eu acho que o sol é quente e vai se transformando em cores.

3.P - [...]. A C1 acha que o sol é tão quente que ele acaba se transformando em cores. Olhe só que coisa mágica, não é mágica? Mas que coisa interessante: tem lá a chuva, a luz do sol, e aí, quando se juntam, forma esse arco-íris com essas cores. Por que acontece isso?

4. C2 - Na minha opinião, eu acho que a luz do sol é quente e a água vai absorvendo as cores do sol.

5. P - A água absorve o quê? [surpresa].

6. $\mathrm{C} 2-$ As cores.

7.P - As cores vêm do sol, então? Ouçam o que a C2 está falando. Ela acha que o sol... O sol não tem uma luz? Quando ele vai embora à noite, não escurece? $\mathrm{O}$ sol aquece e tem essa luz. $\mathrm{E}$ a $\mathrm{C} 2$ acha que o calor do sol, isso que o sol traz, a sua luz, misturando na água, se transforma em cores. Vocês acham que é isso?

8. C3 - O sol não é amarelo? O amarelo do arco-íris não vem do sol?

9. $\mathbf{C} 4-\mathrm{O}$ sol tem cor? $\mathrm{O}$ sol é amarelo?

10. C5 - Eu pinto o sol de amarelo. Quando a gente olha pra ele, ele é amarelo! 11. $\mathbf{P}$ - Olhem, tem mais uma ideia. $\mathrm{C} 5$ diz que o sol é amarelo.

12. C5 - O sol é tão forte, tão forte que forma o arco-íris. Quando encosta nos pinguinhos, forma as cores.

13. C6 - O sol não é amarelo. Eu assisti na $\mathrm{Kika}^{1}$ que o sol tem luz branca...

14. C7 - Eu também assisti. As cores vêm da luz do sol...

15. $\mathbf{P}$ - Mais uma ideia! [surpresa]. E agora, o que a gente decide? A luz do sol é amarela ou branca? Todos concordam que as cores vêm da luz do sol? Será que essa luz tem realmente cores?

16. C7 - Tem sim.

17. P - Vocês ouviram o que a C7 falou? A C7 acha que na luz do sol tem cores. Quem acha também? [as crianças levantam as mãos]. Quem acha que é branca? [algumas crianças levantam as mãos]. Quem acha que é amarelo? [o restante levanta as mãos]. Mas as cores só aparecem quando atravessa os pinguinhos. C5 disse isso. A gente viu isso, não foi? Nós vamos pensar depois em um experimento que ajude a gente a entender melhor isso. Vocês podem já ir pensando em novas ideias. A prô vai pensar também.

Mais uma vez estamos diante de um evento estruturado em perguntas e respostas, não caracterizado, entretanto, como diálogo triádico pelo fato de a professora avaliar as respostas dos alunos e nem os alunos avaliarem as respostas da professora. No turno 1, a professora faz sua pergunta principal, desencadeadora do diálogo que se prossegue. Nos turnos 7, 15 e 17, suas perguntas são mediadoras entre o movimento discursivo dos alunos, que ora afirmam, ora perguntam. Aliás, a

1 A criança se reporta a uma série de programa infantil apresentado em TV brasileira Kika: de onde vem o arco-íris. Disponível em: <https://www.youtube.com/watch?v=Db MigMV10Cc\&noredirect=1 >. Acesso em: 28 out. 2017. 
pergunta do turno 5 tem a intenção clara de enfatizar o que é dito pela criança C2, certamente por ela apresentar um elemento importante, no caso a relação entre a cor da luz solar e a formação do arco-íris. A criança não fala em luz, apenas em cores, é a professora quem, a partir do que é dito pela criança, insere em seu discurso, com uma pergunta (a segunda do turno 7), a relação entre a cor da luz do sol e o arco-íris, apoiando-se nesse signo para mediar o diálogo. Diálogo nada fácil, por sinal, por requerer a construção de uma linguagem capaz de mediatizar a comunicação de conhecimentos científicos complexos para o nível de elaboração da classe e, sem dúvida, da professora também. As perguntas das crianças C3 e $\mathrm{C} 4$, nos turnos 8 e 9, exprimem surpresa e dúvida, pois certamente seus conceitos espontâneos quanto à cor do sol foram postos em xeque. Na linguagem delas, a cor do sol é a aparência do astro, o que aprenderam em seus contextos de brincadeiras, além de ser uma construção cultural, pois não apenas crianças representam o sol e seus raios luminosos de amarelo.

Prosseguindo no diálogo, notamos que há crianças que apresentam outra informação, dessa vez trazida de um programa de TV, a de que a luz do sol é branca. Com isso, constatamos a disputa entre padrões temáticos: para parte da classe, a luz do sol é amarela, e para a outra parte essa luz é branca. Tal disputa parece ser resolvida, ou melhor, adiada, quando a professora convoca a classe para um processo de decisão e de criação de outra experimentação que os levassem a dirimir tais dúvidas.

Notamos também que há outro padrão temático no diálogo, aquele que se refere à interação entre a luz e as gotinhas de água. Em relação ao padrão analisado nos episódios 1 e 2 , constatamos que as crianças apresentam vocábulos novos - a cor da luz do sol, a luz do sol e o verbo encostar, substituído pela professora pelo atravessar -, os quais favorecem as relações semânticas entre significados, gerando um novo processo de significação, em que a enculturação científica começa a configurar-se com novas enunciações. Uma nova totalidade vai formando-se com a junção desses novos elementos, ainda no plano intelectual dos pseudoconceitos, é certo, contudo com mais aproximações ao verdadeiro conceito - o arco-íris se forma quando a luz do sol, de cor branca, encosta ou atravessa as gotinhas de água.

Assistimos a um contexto em que se começa a aprender a falar ciências, no qual os modos de mediação interpostos pela professora, bem como escolhas e decisões tomadas por ela, conduzem a conversa ao novo padrão de significados, além de contribuírem para a continuidade da conversação. Presencia-se um movimento discursivo repleto de indagações autênticas: as crianças fazem perguntas porque querem saber - perguntas que surgem de dúvidas espontâneas e de necessidades geradas no próprio movimento discursivo. $\mathrm{O}$ padrão de interação e de relacionamento criado propicia um clima de confiança, em que as crianças expõem suas ideias sem medo de errar. Não há persuasão nos discursos, e os conhecimentos e recursos utilizados para justificar ou convencer o outro advêm do pouco tempo de escolaridade e das vivências culturais de cada um. Há até o reconhecimento pelas crianças, mediado pela professora, de que existe na classe opiniões diferentes e que se faz necessário criar um novo contexto investigativo para que as dúvidas sejam dirimidas. 


\section{CONCLUSÃO}

Com base nos episódios analisados, concluímos que a comunicação é mediatizada nas aulas de ciências por meio de uma variedade de signos introduzidos pela professora e estudantes, traduzidos e expressos em linguagem, seja por meio das vozes dos sujeitos em interação, seja por ações e gestos. Cada palavra enunciada mostrou o seu significado e o seu papel como signo/instrumento de mediação.

A professora medeia a aprendizagem de conhecimentos físicos, em particular a formação do arco-íris, com a criação de diferenciados contextos de aprendizagem linguísticos e não linguísticos, tais como: sua opção por organizar o ensino de ciências sob orientação investigativa com a instauração do processo investigativo a partir da proposição de um problema, que, por sua vez, levou as crianças a exporem seus conhecimentos prévios e a sugerir ações para resolvê-lo; a transformação das ações sugeridas pelas crianças em atividades investigativas de aprendizagem, orientadas por questões-problema resolvidas com situações experimentais, com a intenção de aproximá-las do fenômeno em estudo e de levá-las a se apropriarem de novos vocábulos, ampliando, assim, o padrão temático da classe; os contextos de conversação, em que se evidenciam padrões de relacionamento e de diálogo favoráveis à comunicação, uma vez que as crianças expuseram opiniões sem medo de errar; a construção de padrões de diálogo não triádicos, com perguntas autênticas proferidas não apenas pela professora, mas principalmente pelas crianças; a valorização da linguagem espontânea ou natural das crianças, na tentativa de se estabelecer pontes entre essa linguagem e a científica; a criação de oportunidades em que as crianças trabalharam em pequenos grupos; a criação de contextos de produções escritas após discussões orais.

Parafraseando Edwards e Mercer (1988), podemos dizer que a professora, em conjunto com seus alunos, criou contextos de aprendizagem, "linguísticos e não linguísticos". Lembramos a tempo que, para esses autores, o termo contexto refere-se a tudo que os participantes em uma conversação conhecem e compreendem, a tudo que lhes ajuda a dar sentido ao que é dito. $\mathrm{O}$ contexto linguístico corresponde ao que se fala, e o não linguístico inclui o tempo e o lugar, a ocasião social, as pessoas envolvidas, suas condutas e gestos.

Presenciamos no movimento dialógico discursivo criado nos diferentes contextos a emergência de elementos que evidenciam o início do processo de enculturação científica, como caracterizam Sasseron e Carvalho (2008, 2014), e o aprender a falar ciências pelas crianças, como propõe Lemke (1997). Com pouca apropriação de significados, é certo, entretanto com ampliação de vocabulário e de relações e de compreensão sobre o fenômeno, como evidenciamos no decorrer da análise. As crianças que experimentaram formar o arco-íris e discutir sobre esse fenômeno coletivamente talvez não falem mais que há um pote de ouro no final do arco e já comecem a empregar os significados construídos em interação com sua professora e colegas de classe, ou talvez transitem entre as duas linguagens, empregando uma e outra, quem sabe aquela que considerar mais adequada para o contexto de conversação em que estiver participando. Será que a criança que pinta o sol de amarelo, uma vez convencida de que a luz desse astro é branca, passará a pintá-lo de branco? 
O movimento dialógico discursivo também evidencia o processo de ensinar e de aprender a ensinar ciências pela professora. Mais precisamente, esse processo de aprendizagem é apreendido pelo conjunto de mediações docente. Mostra uma aprendizagem que acontece continuamente, a cada enunciação sua ou do outro: perguntas e sugestões das crianças levam a professora a criar, escolher e decidir sobre quais signos/instrumentos introduzir no processo de ensino e aprendizagem e quando introduzir. Aprende continuamente com suas parceiras, mediante necessidades emergidas das discussões em grupo e das conversações da sala de aula, tanto em relação ao como ensinar quanto no que diz respeito à necessidade de estudar conteúdos específicos da área de ciências, o que fala do compromisso epistemológico dessa professora, estendido aos docentes participantes do grupo do qual faz parte.

Por fim, reafirmamos a importância de se estudar a linguagem e dialogia em aulas de ciências, sobretudo para buscar fôlego e não desistir de articular as pesquisas acadêmicas dessa área com a necessária renovação do ensino de ciências.

\section{REFERÊNCIAS}

Andrade, I. B.; Martins, I. Discursos de professores de ciências sobre leitura. Investigações em Ensino de Ciências, Porto Alegre: UFRGS, v. 11, n. 2, p. 121-151, 2006. Disponível em: <http://www.if.ufrgs.br/ienci/artigos/Artigo_ID148/v11_n2_a2006. pdf $>$. Acesso em: 29 out. 2017.

Appleton, K.; Kindt, L. Why teach prymary Science? Influences on beginning teacher's pratices. International Journal of Science Education, United Kingdom: Tayloe \& Francis, v. 14, n. 5, p. 291-503, 1992.

Azevedo, M. C. P. S. Ensino por investigação: problematizando as atividades de sala de aula. In: Carvalho, A. M.P.(Org.). Ensino de ciências: unindo a pesquisa e a prática. 1. ed. São Paulo: Pioneira Thomson Learning, 2004. p. 19-33.

Azevedo, M. N. Pesquisa-ação e atividades investigativas na aprendizagem da docência em ciências. Dissertação (Mestrado em Ensino de Ciências) - Universidade de São Paulo, São Paulo, 2008.

. Mediação discursiva em aulas de ciências: motivos e sentidos no desenvolvimento profissional docente. Tese (Doutorado em Ensino de Ciências) — Universidade de São Paulo, São Paulo, 2013a.

Editora, 2013b.

. Ensinar ciências e pesquisa-ação: saberes docentes em elaboração. Jundiaí: Paco

Bakhtin, M. (Voloshínov). Marxismo e filosofia da linguagem. São Paulo: Hucitec, 2010.

Candela, A. Ciência en el aula: los alumnos entre la argumentación y el discurso. México: Paidós, 1999.

Capechi, M. C.; Carvalho, A. M. P.; Silva, D. Relações entre o discurso do professor e a argumentação dos alunos em uma aula de física. Revista Ensaio - Pesquisa em Educação em Ciências. Belo Horizonte: UFMG, v. 2, p. 1-15, 2000. Disponível em: <http://www. scielo.br/pdf/epec/v2n2/1983-2117-epec-2-02-00152.pdf>. Acesso em: 31 out. 2017. 
Carvalho, A. M. P. Formação de professores sobre bases construtivistas (conteúdo: calor e temperatura). In: Universidade de São Paulo; Coordenadoria Executiva de Cooperação Universitária e de Atividades Especiais - CECAE. A universidade e o aprendizado escolar de ciências: Projeto USP/BID. São Paulo: USP; CECAE, 1993. p. 182-189.

Dionne, L. Apprendre à lire, à ecrire et à parler de sciences: un modèle pour guider la croissance dúne communauté d'apprenditissage didactique. Éducation Francophone en Milieu Minoritaire, Ottawa, Université de Moncton, v. 2, n. 1, p. 37-50, 2007.

Edwards, D.; Mercer, N. El conocimiento compartido: el desarrollo da comprensión en aula. Barcelona: Ediciones Paidós, 1988.

Freire, P. Educação como prática da liberdade. Rio de Janeiro: Paz e Terra, 1971.

Freitas, E.T.F: Aguiar Júnior, O. G. A ação docente como sustentação da produção discursiva dos estudantes na sala de aula de física de educação de jovens e adultos. Revista Brasileira de Pesquisa em Educação em Ciências, Belo Horizonte: ABPEC, v. 12, n. 1, p. 9-36, 2012. Disponível em: <https://seer.ufmg.br/index.php/rbpec/article/ view/2421>. Acesso em: 30 out. 2017.

Jan, M.; Chee, Y. S.; TAN, M. E. Changing Science classroom discourse toward doing Science: the design of a game-based learning curriculum. In: Wong, S. L. et al. (Eds.). Proceedings of the 18th International Conference on Computers in Education. Putrajaya, Malaysia: Asia-Pacific Society for Computers in Education, 2010. Disponível em: <http:/www.icce2010.upm.edu.my/papers/c5/short\%20paper/C5SP111.pdf >. Acesso em: 29 out. 2017.

Lem ke, J. L. Aprender a hablar ciencia: lenguaje, aprendizaje y valores. Barcelona: Paidós, 1997.

Lima, M. E. C. C.; Maués, E. Uma releitura do papel da professora das séries iniciais no desenvolvimento e aprendizagem de ciências das crianças. Revista Ensaio - Pesquisa em Educação em Ciências, Belo Horizonte: UFMG, v. 8, n. 2, p. 184-198, jul./dez. 2006. Disponível em: <http://www.scielo.br/pdf/epec/v8n2/1983-2117-epec-8-02-00184. pdf $>$. Acesso em: 29 out. 2017.

López Rodríguez, R.; Jiménez Aleixandre, M. P. ¿Podemos cazar ranas? Calidad de los argumentos de alumnado de primaria y desempeño cognitivo en el estudio de una charca. Enseñanza de las Ciencias, Barcelona: UAB, v. 25, n. 3, p. 309-324, 2007. Disponível em: <http://www.raco.cat/index.php/Ensenanza/article/view/87929>. Acesso em: 29 out. 2017.

Maximo-Pereira, M. Interações discursivas em pequeno grupo durante uma atividade investigativa sobre determinação da aceleração da gravidade. Revista Ensaio-Pesquisa em Educação em Ciências, Belo Horizonte: UFMG, v. 15, n. 2, p. 65-85, maio/ago. 2013. Disponível em: <http://www.scielo.br/pdf/epec/v15n2/1983-2117-epec-15-02-00065. pdf>. Acesso em: 29 out. 2017.

. Memória mediada na aprendizagem de física: problematizando a afirmação "Não me lembro de nada das aulas do ano passado!"Tese (Doutorado em Ensino de Ciências) - Universidade de São Paulo, São Paulo, 2014. 
Mehan, H. Learning lessons: social organization in the classroom. Cambridge, USA: Harward Press, 1979.

Mercer, N. La construcción guiada del conocimiento: el habla de profesores y alumnos. Buenos Aires: Paidós, 1997.

Paidós, 2000.

. Palabras y mentes: cómo usamos el lenguaje para pensar juntos. Barcelona:

Mizukami, M. G. N. Ensino: as abordagens do processo. São Paulo: EPU, 1986.

Monteiro, M. A. A.; Teixeira, O.P. B. Uma análise das interações dialógicas em aulas de ciências nas séries iniciais do ensino fundamental. Investigações em Ensino de Ciências, Porto Alegre:UFRGS, v. 9, n. 3, p. 243-263, 2004. Disponível em <https://www.if.ufrgs. br/cref/ojs/index.php/ienci/article/view/528/324>. Acesso em: 29 out. 2017.

Mortimer, E. F.; Scott, P. H. Atividade discursiva nas salas de aula de ciências: uma ferramenta sociocultural para analisar e planejar o ensino. Investigações em Ensino de Ciências, Porto Alegre: UFRGS, v. 7, n. 2, p. 283-306, 2002. Disponível em: $<$ https://www.if.ufrgs.br/cref/ojs/index.php/ienci/article/view/562/355 >. Acesso em: 29 out. 2017.

Ortega, F. J. R.; Bargalló, C. M.; Alzate, O. E. T. Cambios en la concepciones de los docentes sobre la argumentación e su desarrollo en clase de ciencias. Enseñanza de las Ciencias, Barcelona: UAB, v. 32, n. 3, p. 53-70, 2014.

Paixão, M. F.; Cachapuz, A. La enseñanza de las ciencias y la formación de profesores de enseñanza primaria para la reforma curricular: de la teoria a la práctica. Enseñanza de las Ciencias, Barcelona: UAB, v. 17, n. 1, p. 69-77, 1999.

Pedrancini, V. D.; Corazza-Nunes, M.J.; Galuch, M. T. B. Mediação pedagógica e a formação de conceitos científicos sobre hereditariedade. Revista Electrónica de Enseñanza de la Ciencias, Educacíon Editora, v. 10, n. 1, p. 109-132, 2011. Disponível em: <http://reec.uvigo.es/volumenes/volumen10/ART6_Vol10_N1..pdf>. Acesso em: 29 out. 2017.

Roth, W. M.; Lawless, D. Science, culture and the emergence of language. Science Education, Pennsylvania, USA: v. 86, n. 3, p. 368-85, 2002.

Sasseron, L. H.; Carvalho, A. M. P. Almejando a alfabetização científica no ensino fundamental: a proposição e a procura de indicadores do processo. Investigaçôes em Ensino de Ciências, Porto Alegre: UFRGS, v. 13, n. 3, p. 333-352, 2008. Disponível em: <http://www.if.ufrgs.br/ienci/artigos/Artigo_ID199/v13_n3_a2008.pdf>. Acesso em: 29 out. 2017.

A construção de argumentos em aulas de ciências: o papel dos dados, evidências e variáveis no estabelecimento de justificativas. Ciência $\Xi$ Educação, Bauru: UNESP, v. 20, n. 2, p. 393-410, 2014. Disponível em: <http://www.scielo.br/pdf/ciedu/ v20n2/1516-7313-ciedu-20-02-0393.pdf>. Acesso em: 29 out. 2017.

Scarinci, A. L.; Pacca, J. L A. O professor de física em sala de aula: um instrumento para caracterizar sua atenção. Investigaçôes em Ensino de Ciências, Porto Alegre: UFRGS, v. 14, n. 3, p. 457-477, 2009. Disponível em: <http://www.if.ufrgs.br/ienci/artigos/ Artigo_ID226/v14_n3_a2009.pdf>. Acesso em: 29 out. 2017. 
SouzA, V.F. M. A importância da pergunta na promoção da alfabetização científica em aulas investigativas de física. Dissertação (Mestrado) - Faculdade de Educação, Instituto de Física, Instituto de Química e Instituto de Biociências, Universidade de São Paulo, São Paulo, 2012.

Vieira, R. D.; Nascimento, S. S. Uma visão integrada dos procedimentos discursivos didáticos de um formador em situações argumentativas de sala de aula. Ciência E̋ Educação, Bauru: UNESP, v. 15, n. 3, p. 443-457, 2009. Disponível em: <http://www. scielo.br/pdf/ciedu/v15n3/01.pdf>. Acesso em: 29 out. 2017.

Vigotsкi, L. S. A construção do pensamento e da linguagem. São Paulo: Martins Fontes, 2009. - A formação social da mente: o desenvolvimento dos processos psicológicos superiores. São Paulo: Martins Fontes, 2010.

Wertsch, J. V. La mente en acción. Argentina: Aique, 1999.

\section{SOBRE AS AUTORAS}

Maria Nizete de Azevedo é doutora em educação em ensino de ciências pela Universidade de São Paulo (USP). Professora da Universidade Federal do Estado de São Paulo (UNIFESP).

E-mail: marianizete@gmail.com

Maria Lúcia Vital dos Santos Abib é doutora em educação pela Universidade de São Paulo (USP). Professora da mesma instituição.

E-mail:mlabib@usp.com.br

Recebido em 17 de abril de 2015 Aprovado em 25 de novembro de 2016 